Article

\title{
On the Application of Small-Scale Turbines in Industrial Steam Networks
}

\author{
Ansgar Weickgenannt ${ }^{1, *,+}$, Ivan Kantor ${ }^{2,3,+} \mathbb{D}$, François Maréchal ${ }^{2} \mathbb{D}$ and Jürg Schiffmann ${ }^{1, *}$ \\ 1 EPFL-LAMD, Rue Maladière 71b, 2002 Neuchâtel, Switzerland \\ 2 EPFL-IPESE, Rue de l'Industrie 17, 1951 Sion, Switzerland; ivan.kantor@epfl.ch (I.K); \\ francois.marechal@epfl.ch (F.M) \\ 3 HES-SO Valais-Wallis, 1950 Sion, Switzerland \\ * Correspondence: ansgar.weickgenannt@bluewin.ch (A.W.); Jurg.Schiffmann@epfl.ch (J.S.) \\ + These authors contributed equally to this work.
}

Citation: Weickgenannt, A.; Kantor,

I.; Maréchal, F.; Schiffmann, J. On the Application of Small-Scale Turbines in Industrial Steam Networks.

Energies 2021, 14, 3149. https://

doi.org/10.3390/en14113149

Academic Editors: Patrik Thollander, Thomas Zobel and Valentina Colla

Received: 16 March 2021

Accepted: 21 May 2021

Published: 28 May 2021

Publisher's Note: MDPI stays neutral with regard to jurisdictional claims in published maps and institutional affiliations.

Copyright: (c) 2021 by the authors. Licensee MDPI, Basel, Switzerland. This article is an open access article distributed under the terms and conditions of the Creative Commons Attribution (CC BY) license (https:// creativecommons.org/licenses/by/ $4.0 /)$.
Abstract: This study investigates the technical and economic feasibility of replacing throttling valves with smale-scale, oil-free turbomachinery in industrial steam networks. This is done from the perspective of the turbomachine, which has to be integrated into a new or existing process. The considered machines have a power range of $P=[0.5, \ldots, 250 \mathrm{~kW}]$ and have been designed using real industrial data from existing processes. Design guidelines are developed, which take into account the thermodynamic process as well as engineering aspects of such a turbomachine. The results suggest that steam conditioning prior to heat exchange could be completed by small expanders to produce mechanical work, reducing exergy destruction and improving site-wide energy efficiency compared to throttling valves. Cost estimates for such machines are presented, which serve as a basis for case-specific investment calculations. The resulting payback times of less than 18 months highlight the economic potential such solutions.

Keywords: industrial steam networks; oil-free; small-scale turbomachinery; process integration; exergy; energy recovery

\section{Introduction}

\subsection{Theoretical Background and Application Context}

Steam is often used in industrial processes to transport heat. In small industrial installations, steam is typically generated at a single pressure level, according to the needs of the most demanding process such as an oven, an evaporator, or a reaction vessel. In larger installations, steam is distributed at multiple pressure levels to service the needs of various units throughout the plant using pressurized steam [1]. Conversion of steam to mechanical work is typical for large installations, where central utility plants use large turbines to manage steam distribution at different pressure levels, while co-generating electricity. However, steam supplied to the plant is usually done at coarse pressure intervals determined by the process needs. With hundreds of heat exchange operations carried out across large plants, steam received at the distribution conditions must be conditioned to reach the appropriate pressure for each individual heat exchanger. One consequence of selecting distribution pressures for a variety of processes is that the steam pressure in the network is determined by the highest pressure and temperature requirement of a process. For each heating requirement within the network, the steam must be conditioned to the desired pressure and temperature values prior to entering the steam heat exchanger, which is typically accomplished by simple throttling [2]. In this study, the potential of adding small-scale turbomachinery for steam conditioning is investigated to assess the potential for such technology in large process systems. 
In typical applications, the amount of thermal energy that can be released as heat in the superheated steam region is significantly smaller than that in the two-phase region of the steam.

$$
\frac{q_{\text {sup }}}{q_{\text {cond }}}=\frac{q_{\text {sensible }}}{q_{\text {latent }}}<1
$$

The heat release $q$ will therefore essentially take place in the two-phase region, thus at a constant condensation temperature. This may be advantageous for many processes, as it simplifies the design of the heat exchanger and the process control. One example process is that of an oven, where the smallest possible temperature gradients in the baking chamber are required.

The conditioning of superheated steam originating from the steam generator is typically carried out in two steps, as illustrated in a descriptive Temperature-Entropy (TS) diagram (Figure 1). In the first step $(1 \rightarrow 2)$, the steam is expanded at constant enthalpy $h$ to the pressure $(p)$ that corresponds to the required condensation temperature $(T)$ in the two phase region. In the second step $(2 \rightarrow 3)$, which is isobaric, heat $q=\int T d s$ is released up to the saturated vapor pressure line, whereby the steam cools down accordingly. The saturated steam obtained by the conditioning condenses, releasing heat at constant temperature $T_{\mathcal{c}}$. The two steps are technically realized by connecting a throttling device with a heat exchanger or desuperheater in series.

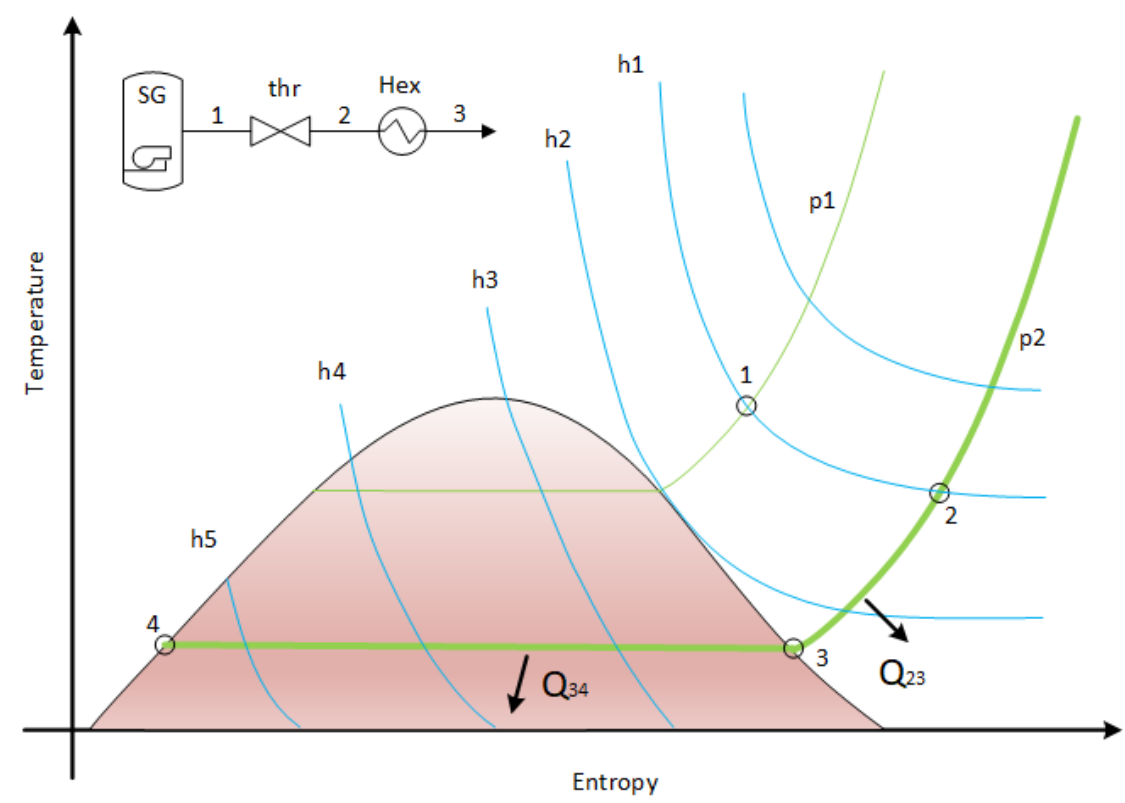

Figure 1. Steam conditioning with throttle and heat exchanger shown in a TS diagram, SG: Steam Generator, thr: Throttle, Hex: Heat exchanger.

Reaching saturation after throttling in such industrial applications also typically includes a desuperheater, where water is injected to achieve saturation conditions and also increase the steam flow. This part of the application is not considered in this work as the focus is to valorise the required pressure drop as work instead of by throttling.

An alternative to this conditioning process is to add a turbine, to recover the energy released as mechanical work. Moreover, the use of a turbine is indicated, if the heat released in step two of the conditioning process is not further used in another process and discharged as waste heat. With regard to the imperatively need to reduce $\mathrm{CO}_{2}$ emissions in technical processes, releasing this energy to the environment should be avoided.

\subsection{Small-Scale Turbomachinery}

Small-scale turbomachinery typically ranges in power from a few watts to a few hundred $\mathrm{kW}$, with high rotor speeds being a characteristic feature of such machines. Begin- 
ning in the 2000s, advances in small-scale gas turbines were made by various researchers. In 2004, Epstein [3] described the current status with a comprehensive study of the MIT "shirt-button" gas turbine project as a whole, with a particular focus on manufacturing. In 2006, Isomura et al. [4] demonstrated the feasibility of a small-scale compressor rotating at $720 \mathrm{krpm}$, reaching a pressure ratio slightly higher than 2 at a measured isentropic efficiency in excess of $60 \%$, using a 3D impeller wheel. Since then, intensive research has been carried out in the field of small oil-free turbomachinery, especially for ORC (Organic Rankine cycle) processes, heat pumps and fuel cell applications. In the power range of a few $\mathrm{kW}$, Schiffmann [5] showed in 2009 the technical feasibility with an electrically-driven refrigerant compressor. The shaft was supported by herringbone grooved journal bearings, lubricated by the processed working fluid (R134a), thus offering a fully oil-free and hermetic solution. The shaft rotated up to $210 \mathrm{krpm}$ and a pressure ratio higher than 3.3 was achieved. The radial compressor shown by Demierre [6] in 2015 was driven by a radial inflow turbine using gas-lubricated bearings. This oil-free machine was operated up to shaft speeds of $200 \mathrm{krpm}$. In their experiments, compressor and turbine pressure ratios of up to 2.8 and 4.4, respectively, were achieved with an isentropic efficiency of $70 \%$. A micro steam turbine with a tip diameter of $15 \mathrm{~mm}$ was presented recently by Wagner [7]. The partial admission radial steam turbine was connected to a fan to drive an anode off-gas recirculation loop for solid oxide fuel cell stacks. This rotor was supported on dynamic steam-lubricated gas bearings and reached a maximum speed of $175 \mathrm{krpm}$. In the work by Rosset [8] in 2021, the experimental results of a novel turbogenerator used in an ORC cycle are presented. The single-stage radial inflow turbine and the generator rotor coupled on the same shaft were supported with aerodynamic bearings lubricated by the ORC working fluid (R245fa). The turbogenerator achieved an electrical power output of $2.3 \mathrm{~kW}$ with an overall peak efficiency of $67 \%$. The electromechanical efficiency of the turbogenerator reached $91 \%$. These examples of gas-bearing supported turbomachinery clearly suggest that both small-scale turbocompressors and turbines are technically feasible, while offering competitive efficiency, oil-free operation and high power densities.

The components of small scale turbomachinery, such as the impeller, the rotor with its bearing arrangement, and the electrical machine can no longer be treated separately. They have to be considered in a coupled approach in the design phase to obtain feasible and efficient machines, in particular, because the interrelationships between the different components are often nonlinear [9]. This means that when designing a small-scale turbine, not only fluid mechanical and thermodynamic aspects (specific enthalpy difference, volume flow, rotor speed) should to be taken into account, but also (due to the very high rotor speeds), rotordynamic aspects, material selection and the entire bearing design. Since the machines discussed here are inserted into the process as replacements for existing components, commercial considerations also influence the design as a third factor, leading to the final selection the machine type.

\section{Thermodynamic Process Design}

The turbine, which could be used in addition to the throttle valve for conditioning the steam can be characterized with two process parameters, namely its expansion ratio $\pi_{t}$ and its efficiency $\eta_{i s}$. Typical stage expansion ratios are up to $\pi_{t}=4-5$ with acceptable efficiency [10]. If the required expansion ratio is larger than $\pi_{t}$, more than one stage could be connected in series. The turbine efficiency has typical values in the range $\eta_{i s}=[0.7, \ldots .0 .9]$. For the sake of simplicity, the following assumptions in the analysis are made: the isentropic efficiency is used to characterize the turbine, the expansion is considered adiabatic and the kinetic and potential energy changes of the steam are assumed to be negligible during the conversion from thermal to mechanical energy.

To assess the use of a turbine in a given steam conditioning application, a generalized expansion process can be used. This expansion process can be represented by an expansion line in a TS diagram, shown in Figure 2 and is constructed as follows: from the initial conditions (state 1$)$, the steam is expanded by isenthalpic throttling $(\mathrm{h}=\mathrm{cst})$ to the turbine 
inlet pressure $p_{2^{\prime}}$, (state $\left.2^{\prime}\right)$ in Figure 2. Contrary to conventional approaches for turbine calculations, the temperatures and pressures are not all known a priori, as they depend on the locus of state 3 , which defines the turbine outlet conditions and the turbine efficiency $\eta_{i s}$. The unknown turbine inlet pressure $p_{2^{\prime}}$ can be determined from the given turbine outlet pressure $p_{3}$ at state 3 and the efficiency of the turbine $\eta_{t, i s}$. Based on the definition of the isentropic turbine efficiency [11], Equation (2), the turbine outlet state $h_{3, \text { is }}$ for a reversible adiabatic expansion is calculated using Equation (3). The calculations are included here for completeness.

$$
\begin{gathered}
\eta_{t, i s}=\frac{\left(h_{3}-h_{2^{\prime}}\right)}{\left(h_{3, i s}-h_{2^{\prime}}\right)} \\
h_{3, i s}=h_{2^{\prime}}+\frac{\left(h_{3}-h_{2^{\prime}}\right)}{\eta_{t, i s}}
\end{gathered}
$$

In the next step, the corresponding entropy $s_{3, i s}$ is determined using an equation of state. If the turbine outlet state $h_{3, i s}$ after the adiabatic isentropic expansion is located in the wet steam area (Figure 2), the entropy $s_{3, i s}$, Equation (4), can be computed by means of the steam quality $x$, Equation (5).

$$
\begin{gathered}
s_{3, i s}=s^{\prime}+x \cdot\left(s^{\prime \prime}-s^{\prime}\right) \\
x=\frac{\left(h_{3, i s}-h^{\prime}\right)}{\left(h^{\prime \prime}-h^{\prime}\right)}
\end{gathered}
$$

Because $s_{3, i s}=s_{2^{\prime}}$, the entropy at state $\left(2^{\prime}\right)$ is known. Finally, the turbine inlet pressure can be calculated:

$$
p_{2^{\prime}}=p_{2}\left(h_{2^{\prime}}, s_{2^{\prime}}\right)
$$

The analysis shown here is only valid if the turbine exit pressure is located on the saturated vapor line. However, if this is not the case, an analogous procedure can be established to determine the turbine inlet pressure $p_{2^{\prime}}$. The knowledge of the turbine inlet pressure $p_{2^{\prime}}$ enables calculation of the total expansion ratio $\pi_{t}=p_{2^{\prime}} / p_{3}$. Thus the number of stages needed to match the total expansion ratio can be determined as the product of $N$ stages in series.

$$
\pi_{t}=\prod_{i=1}^{N} \pi_{i}
$$

where $\pi_{i}$ is the pressure ratio of the single stage $i$.

The generalized expansion curve is obtained by varying the turbine inlet state $h_{2^{\prime}}\left(p_{2^{\prime}}, s_{2^{\prime}}\right)$ at fixed turbine outlet state $h_{3}(p 3, T 3)$ and given constant turbine efficiency $\eta_{\text {is }}$. In Figure 2, these states are connected by a straight line, termed the expansion line. The slope $f^{\prime}(s)=d T / d s$ of the expansion line in a TS diagram is related to the turbine efficiency. At an isentropic expansion, the slope becomes $f^{\prime}(s)=\infty$, i.e., a vertical line. This design method reveals an interesting feature, namely that the work output of the turbine is independent of the efficiency, because enthalpy difference remains constant considering state 3 is invariant.

$$
-w_{t, \max }=h_{3}-h_{2^{\prime}}=\text { constant }
$$

Conversely, the expansion ratio $\pi_{t}$ between turbine inlet and outlet increases with decreasing turbine efficiency and vice versa. This allows prediction of the financial benefit from the application without knowing detailed turbine specifications at an early project phase. 


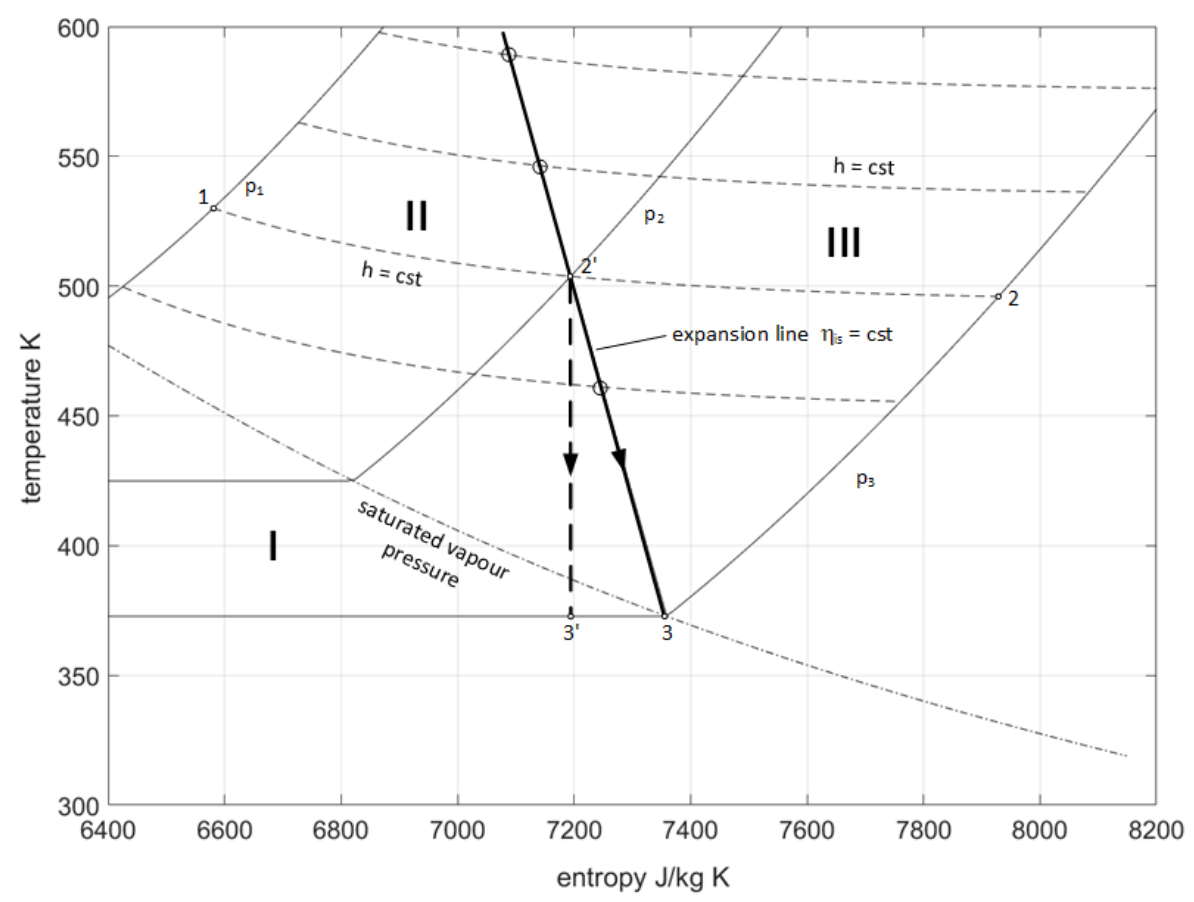

Figure 2. Graphical representation of the expansion line for a constant turbine efficiency $\eta_{\text {is }}$.

Using the expansion line and the saturated vapor pressure line, three different scenarios of steam conditioning using a turbine can be distinguished, depending on the initial state of the steam $h_{1}\left(p_{1}, T_{1}\right)$ leaving the steam generator.

1. In the first scenario, the initial state of the steam $h_{1}\left(p_{1}, T_{1}\right)$ corresponds to a location within the two-phase region (I). The reduction of the initial temperature of the steam to the required process temperature can be achieved directly by an expansion at constant enthalpy using the Joule-Thomson effect. Further conditioning of the steam is not necessary and heat is not rejected to the environment. Moreover, the amount of heat that can be transferred in the process is increased by the expansion, since the entropy rises $d q=T d s$. In this case, the use of a turbine is inappropriate. This scenario is unlikely to occur in an industrial setting as steam is typically distributed at superheated conditions to avoid condensation and reduce heat losses in the distribution network.

2. In the second scenario (II), left side of Figure 3, the initial state of the steam is situated between the saturated steam line and the expansion line. The desired turbine inlet condition can be reached by first expanding the steam by isenthalpic throttling to the expansion line $\left(1 \rightarrow 2^{\prime}\right)$. Further expansion of the steam is then carried out by the turbine until it reaches the state on the saturated steam line $\left(2^{\prime} \rightarrow 3\right)$. In the TSdiagram, the expansion line is added to illustrate the concept for the process designer. The two process steps above can be interchanged, whereby the turbine has to operate at higher pressure and temperature. Expansion by the turbine is carried out into the two-phase region until that pressure is reached from which it can be further expanded at constant enthalpy down to the saturated state. It is assumed that the same turbine efficiency is used, i.e., that the expansion line is shifted parallel to the left. Expansion in a turbine can continue to the required condensation temperature; however, this penalizes the amount of available heat. Furthermore, such operation increases the risk of wear of the flow-guiding components of the turbine from erosion, which should be avoided. This emphasizes the importance of properly selecting the turbine outlet state $h_{3}\left(p_{3}, T_{3}\right)$. The closer state (3) is to the saturated vapor pressure line, the more work (Equation (8)) can be extracted from the process. However, to reduce the risk of expansion into the two-phase region, a superheating margin of the steam would be of advantage. 
3. The third scenario (III) is characterized by an initial state of the steam that is located to the right of the expansion line, shown on the right side of Figure 3. The required target state on the saturated vapor pressure line cannot be achieved solely by a turbine. Enabling the use of turbine in this scenario requires a certain amount of thermal energy to be released as heat. In a first step $\left(1 \rightarrow 2^{\prime \prime \prime}\right)$, the temperature of the steam is lowered at constant pressure to the corresponding turbine outlet temperature while releasing heat. In the second step $\left(2^{\prime \prime \prime} \rightarrow 3\right)$, the steam is expanded to the final state by the turbine. As discussed in the previous case, the two process steps are interchangeable. Graphically, this is done by a parallel shifting of the expansion line in Figure 3 to the right until the initial state of the steam is reached (state 1). After expansion in a turbine $\left(1 \rightarrow 2^{\prime \prime}\right)$, the turbine outlet temperature is obtained as the intersection point with the isobaric pressure corresponding to the condensation pressure. In the second step $\left(2^{\prime \prime} \rightarrow 3\right)$, the superheated steam is cooled to the saturation temperature after entering the heat exchanger. If $q_{2^{\prime \prime} 3}$ is small, the process heat exchanger will transfer heat initially in the superheated steam region to reach saturation conditions and thus modification of the design would not be necessary.
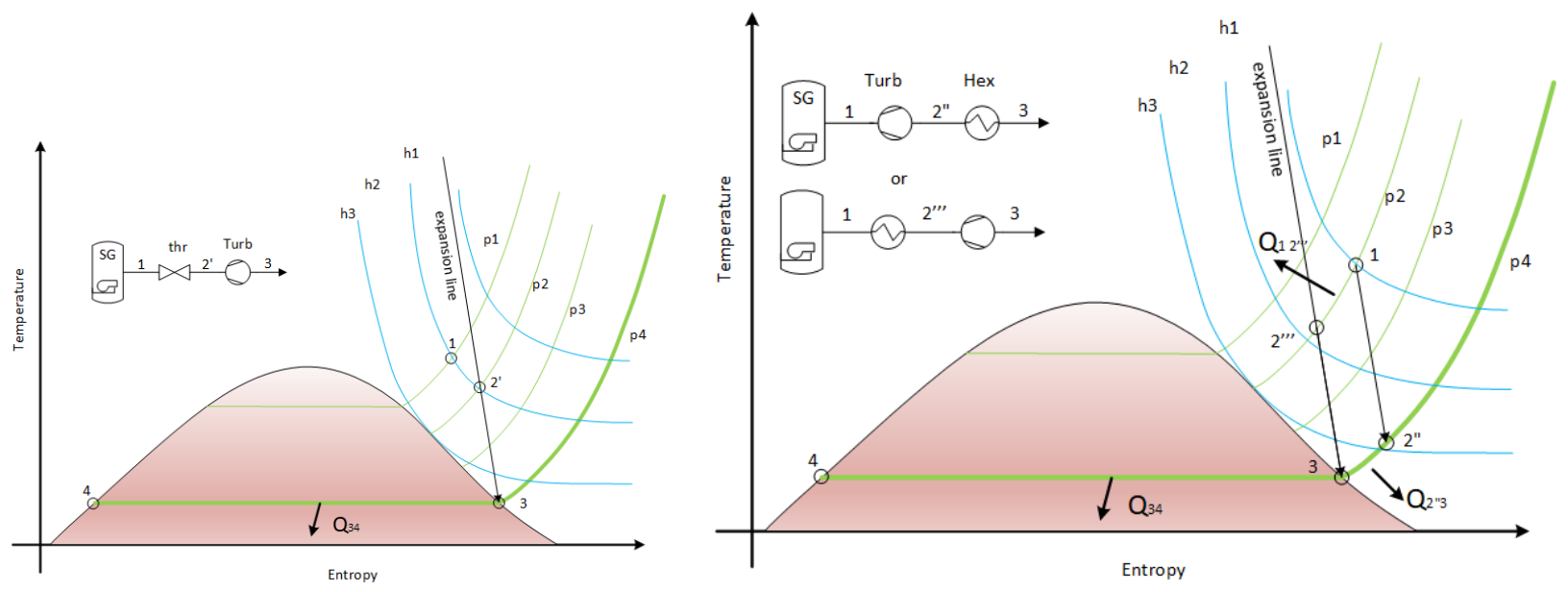

Figure 3. Improved steam conditioning processes; (left): second scenario (II), using throttle and turbine; (right): third scenario (III), using turbine and heat exchanger.

\section{Design Challenges for Small-Scale Turbines}

Recently, small-scale turbomachinery supported on gas lubricated bearings have been tested successfully in a variety of applications such as heat pumps [5], air conditioning systems, fuel cells [12] and organic Rankine cycles [8]. This work focuses on the use of small-scale turbines with gas-lubricated journal bearings, which operate with superheated steam close to the saturated vapor pressure and for which the working fluid directly serves as the bearing lubricant, thus offering a hermetic system. However, this introduces additional challenges, because of the risk of condensation in the journal bearings, as recently highlighted by Guenat and Schiffmann [13].

Progress in research makes it possible to use gas-lubricated bearings in such turbomachines for applications in the power range of $P=[0.5-250 \mathrm{~kW}]$, see [14]. As the lubrication is provided by the working fluid, they are inherently oil-free, thus eliminating concerns of contamination of the working fluid by lubricants or vice versa. This feature is advantageous, since it prevents premature deterioration of both the working fluid and lubricant properties and simplifies the design of the turbomachine. Both factors significantly reduce the operational and investment costs.

Conversely, this means that the operating point of the turbomachine, thus thermodynamic state of the working medium $(p, T)$ in the turbine imposes design constraints 
upon the other parts of the machine. Special care must be taken in the design of the main components such as:

- $\quad$ the impeller

- seal

- $\quad$ rotor with permanent magnets

- thrust and journal bearings

- the electrical stator

as shown in Figure 4. A comprehensive discussion about the design of single components is given by Schiffmann et al. [14].

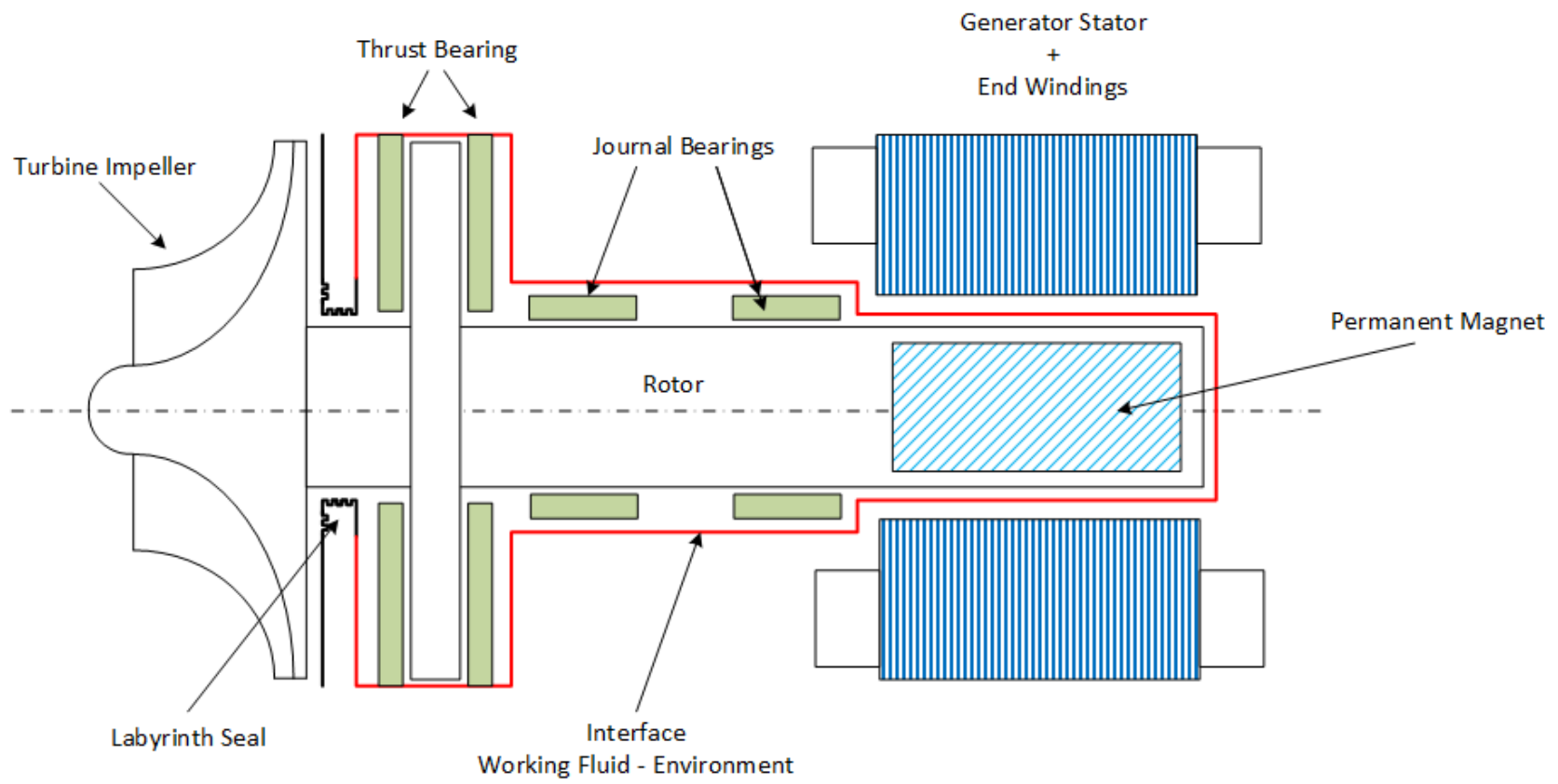

Figure 4. Schematic layout of a small-scale turbine using vapor as lubricant.

In the steam conditioning process, the turbine operates close to the vapor saturation pressure; therefore, special care must be taken to avoid condensation in the bearings to avoid a reduction in load capacity and rotor dynamic stability [13]. Due to the functional principle of a fluid dynamic bearing, an isothermal pressure increase occurs inside the bearing. Hence, the vapor temperature surrounding the bearings has be high enough that the maximum bearing pressure is lower than the saturation vapor pressure to prevent condensation. Furthermore, with a low pressure of the steam in the motor, the windage loss between rotor and stator is reduced [14].

As a consequence, it is necessary to separate the turbine rotor backspace from the rest of the spindle, which can be done with a labyrinth seal. It acts mainly as a throttle and therefore limit leakage bypassing the turbine rotor. Details on the design of these seals with a special focus on small-scale turbomachines can be found in the work of Katuwal Chhetri [15].

Therefore, the remaining leakage flow across the seal still has a higher temperature than the steam at the turbine exit. This steam temperature must not exceed the Curie temperature of the permanent magnet, else the magnetic properties are lost and the generator fails. For the stator of the generator including the end-winding, its insulation class determines the temperature limit. Class $\mathrm{E}$ is commonly used for cost reasons and has a limit temperature of $T=393 \mathrm{~K}$. In case a physical separation of the stator from the rotor and bearing can be applied, the stator can be cooled separately and high steam temperatures in the motor can be tolerated. However, any condensate that forms on the cold separation surface must be removed such that it cannot penetrate into the bearings. Purging of the 
motor housing with conditioned steam originating from the turbine inlet could be an option to address this.

The single-stage machine shown in Figure 4 has an overhung radial turbine on one side and the generator on the other with the bearings located in between. Multi-stage turbines are also possible. As indicated in Section 2, the working fluid is superheated steam and the process should be managed to avoid wet steam at the turbine exhaust to avoid droplet erosion. However, due to the proximity to the saturated steam line, droplet formation may occur locally.

\section{Evaluation of Steam Conditioning Based on Test Cases}

In addition to the thermodynamics of the process and the design aspects of using an oilfree, small-scale turbine for the steam conditioning, the commercial perspectives of such an application have to be considered as well. This requires realistic test cases from the industry and cost estimates for the necessary investment and operational costs, including benefits from generated electricity. From the 20 available cases (Appendix A: Tables A1 and A2), four are selected and summarised in Table 1, representing typical examples for steam conditioning processes as they occur in industry $[1,16]$.

Table 1. Sample of typical steam conditioning cases from industry.

\begin{tabular}{|c|c|c|c|c|}
\hline & Case 1 & Case 2 & Case 3 & Case 4 \\
\hline supply pressure [barg] & 40 & 40 & 40 & 40 \\
\hline supply steam temperature $[\mathrm{K}]$ & 550.00 & 550.00 & 550.00 & 550.00 \\
\hline target pressure [bar] & 1.0 & 2.7 & 5.19 & 29.63 \\
\hline steam flow rate $\dot{m}[\mathrm{~kg} / \mathrm{s}]$ & 0.033 & 0.178 & 0.078 & 0.253 \\
\hline $\begin{array}{l}\text { expansion ratio by throttling } \\
\qquad\left(h=c^{s t}\right)[-]\end{array}$ & 40 & 14.8 & 7.7 & 1.35 \\
\hline expansion scenario (see Section 2) & II & II & II & III \\
\hline specific enthalpy difference $\Delta h_{2^{\prime} 3}[\mathrm{~kJ} / \mathrm{kg}]$ & -218 & -173 & -143 & -65.7 \\
\hline turbine expansion ratio $\eta=0.8$ & 4.25 & 3 & 2.45 & 1.35 \\
\hline turbine power $P=\dot{m} \cdot\left|\Delta h_{2^{\prime} 3}\right|[\mathrm{kW}]$ & 7.27 & 30.8 & 11.12 & 13.29 \\
\hline
\end{tabular}

The mass flow through the turbine is in a range of $\dot{m}=[0.033, \ldots, 1.376 \mathrm{~kg} / \mathrm{s}]$. This suggests selection of mixed-flow turbines offering a less expensive alternative to axial machines [10], especially at small mass flowrates, where the axial machine tends to be fragile due to the necessarily large number of blades. For the mass flow range and pressure ratios, the turbine radius $r_{4}$ is in a range of $r_{4}=[10, \ldots, 50 \mathrm{~mm}]$ and the rotational shaft speed lies between $N_{\text {turb }}=[51,000, \ldots, 400,000 \mathrm{rpm}]$, (refer to Table A3 in Appendix A). For the given turbine radius, the application of gas bearings proposed in the previous section are particularly suitable and inexpensive for the high rotational speeds required. In addition, the nozzle ring can be omitted on radial machines, if the required expansion ratio is small. Generally, radial or mixed-flow turbines are more compact in axial direction. From a rotordynamic perspective, a mixed-flow turbine is preferable, because the rotor tends to be shorter than its axial counterpart, thus its Eigenfrequency involving lateral bending is higher, which is beneficial for gas bearing supported rotors [9]. For cases 1-3 listed in Table 1 , the expansion ratio of the turbine necessary to expand from $\left(p_{2^{\prime}}(\eta) \rightarrow p_{3}\right)$ for a turbine efficiency $\eta=0.8$ is given. It is significantly smaller than the expansion ratio by throttling at constant enthalpy only $\left(p_{1} \rightarrow p_{3}\right)$.

In the TS diagram shown in Figure 5, the expansion using a turbine with different efficiencies $\eta=[0.7,0.8,0.9,1]$ is shown for Case 1 . The negative slope of the expansion line (see Section 2) increases with increasing turbine efficiency $\eta$, whereas the turbine inlet pressure $p_{2^{\prime}}(\eta)$ and inlet temperature $T_{2^{\prime}}(\eta)$ decreases for reaching the same state (state 3 ) from Table 2. Consequently, in most practical applications, a single-stage or two-stage turbine would be sufficient to cover the process requirements, which simplifies the overall design and therefore reduces the investment cost. Moreover, lower turbine inlet pressures simplify the design of the turbine casing and the labyrinth seal needed to maintain low pressures in the bearing and generator housing. The fourth case in Table 1 represents 
scenario III, where the energy output is dependent on the turbine efficiency. However, inlet and outlet pressure of the turbine are very high, i.e., the opposite of cases 1-3 with the corresponding consequences concerning the casing and sealing.

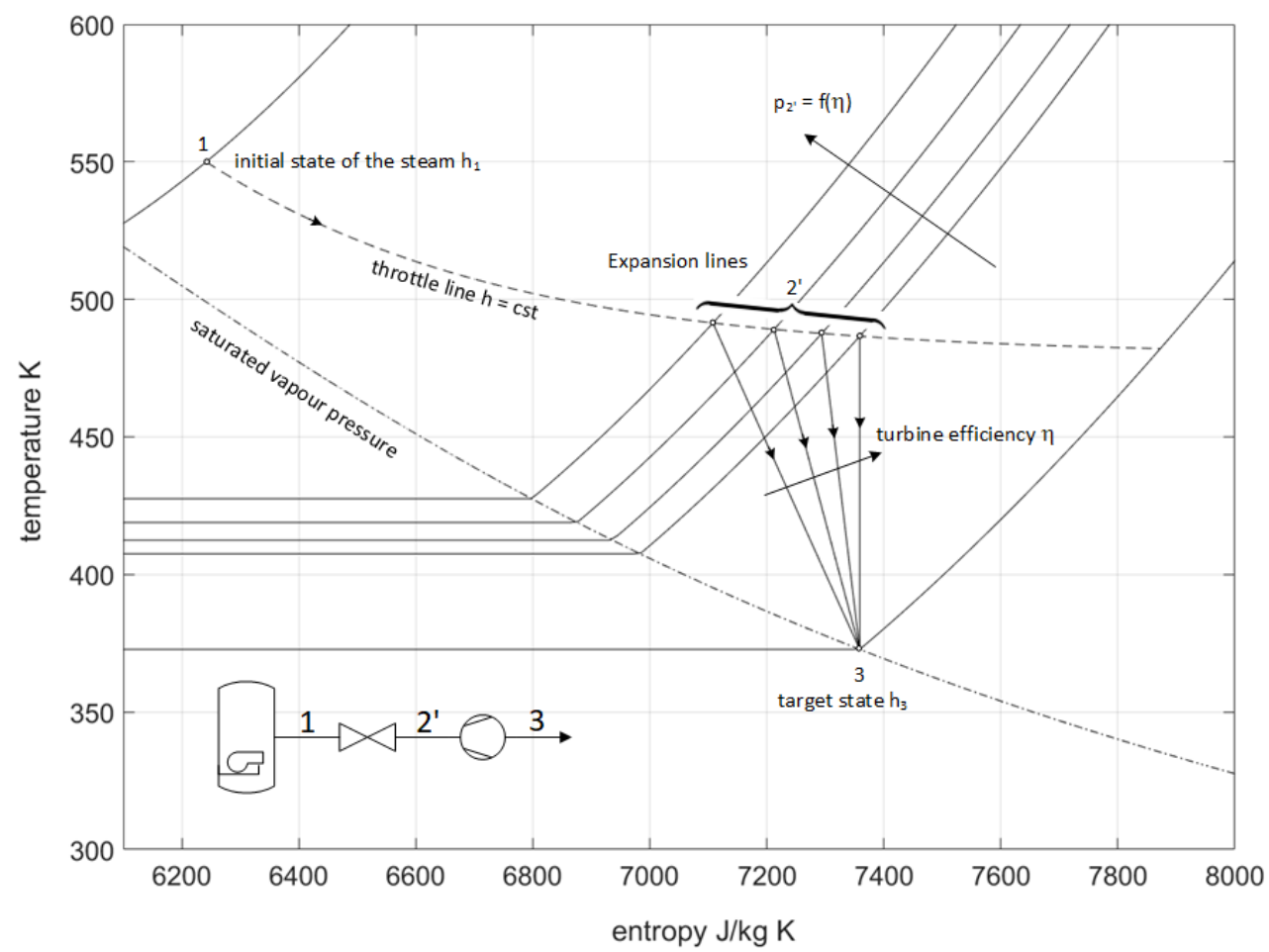

Figure 5. Case 1, Table 1, single expansion for different turbine efficiencies $\eta=[0.7,0.8,0.9,1]$.

Table 2. Test case 1 (from Table 1), necessary turbine expansion ratio as a function of turbine efficiency.

\begin{tabular}{lcccc}
\hline Efficiency $\boldsymbol{\eta}$ & $\mathbf{0 . 7}$ & $\mathbf{0 . 8}$ & $\mathbf{0 . 9}$ & $\mathbf{1}$ \\
\hline pressure ratio $\pi_{2^{\prime} 3}$ & 5.35 & 4.25 & 3.55 & 3.07 \\
turbine inlet temperature $[\mathrm{K}]$ & 491.4 & 489.1 & 487.6 & 486.6 \\
\hline
\end{tabular}

The turboexpander system cost $\left(C_{T}\right)$ depends on (i) the power of the machine, (ii) the pressure and temperature level at which the machine is operated and (iii) the turbine specification (mass flow, expansion ratio, efficiency, number of stages, etc.). However, the key parameter to estimate costs remains the power rating of the machine. Thus, a linear relationship is selected to estimate the system costs as a function of the generated power P, shown in Equation (9), which represents the cost of the machine under conditions of large-scale manufacturing leveraging the economies of scale for production.

$$
C_{T}=A \cdot P+B
$$

where $A \approx 150 \frac{\mathrm{CHF}}{\mathrm{kW}}$ and $B \approx 4000 \mathrm{CHF}$. The currency used for the analysis is the Swiss Franc $(\mathrm{CHF})$, considered here due to the location of equipment manufacturers and related economic parameters.

The authors are aware of the fact that other methods are commonly used to estimate the scaling sensitivity. In the chemical industry for example, the change of investment costs caused by scaling effects are often described by a power function with the exponent of $n=6 / 10$, see Williams [17] and Peters [18]. However, the linear fit proposed here is obtained by assessing the prototyping costs for several similar machines tested by the research group of the authors [19]. 
The presented cost estimate is used to determine the investment costs for the turbine in the case studies, shown in Table 3, with the payback period ( $\mathrm{PbP})$ modeled related to the electricity price (EPE):

$$
P b P=\frac{A \cdot P+B}{E P E \cdot P}
$$

Rearranging Equation (10) yields

$$
P b P=\lim _{P \rightarrow \infty}\left(\frac{A}{E P E}+\frac{B}{E P E} \cdot \frac{1}{P}\right)=\text { constant }
$$

with an average electricity cost in Switzerland of EPE $=0.2 \mathrm{CHF} / \mathrm{kWh}[20$ ] as a basis, a turbine output of $P_{e l}=7.27 \mathrm{~kW}$ (Case 1 in Table 1) results in economic break-even after ca. $\mathrm{t}=3500 \mathrm{~h}$. If the electrical energy is fed back into the public grid, the compensation is around $E P E_{\text {Back }}=0.07 \mathrm{CHF} / \mathrm{kWh}$, tripling the payback time, $t_{\text {back }}=10,000 \mathrm{~h}$. If the system is operated continuously for 11 months per year (approx. $8000 \mathrm{~h}$ ), the investment cost is returned after 4.4 months in case of internal consumption and after 1.25 years in the case of re-injection into the electricity grid. As the machines are maintenance-free, no additional operating costs are considered.

Table 3. $\mathrm{PbP}$ for the four cases studied in detail, $\mathrm{EPE}=0.2 \mathrm{CHF} / \mathrm{kWh}, \mathrm{EPEback}=0.07 \mathrm{CHF} / \mathrm{kWh}$.

\begin{tabular}{lcccc}
\hline & Case $\mathbf{1}$ & Case 2 & Case 3 & Case 4 \\
\hline turbine power $\mathrm{P}[\mathrm{kW}]$ & 7.27 & 30.8 & 11.12 & 13.29 \\
\hline $\mathrm{C}_{T}[\mathrm{CHF}]$ & 5100 & 8620 & 5670 & 6000 \\
\hline $\mathrm{PbP}(\mathrm{EPE}=0.2 \mathrm{CHF} / \mathrm{kWh})[\mathrm{h}]$ & 3500 & 1400 & 2550 & 2260 \\
$\mathrm{PbP}(\mathrm{EPEb}) \mathrm{kack}=0.07 \mathrm{CHF} / \mathrm{kWh})[\mathrm{h}]$ & 10,000 & 4000 & 7780 & 6450 \\
\hline
\end{tabular}

In Figure 6, the $\mathrm{PbP}$ is shown as a function of the generated electrical power for 20 industrial cases. The pressure of the steam from the steam generator is the same for all cases $\left(p_{1}=4 \mathrm{MPa}\right)$. The investigated cases differ in the final pressure (state 3 ) to be achieved, which is in the range of $p_{3}=[0.1, \ldots, 2.458] \mathrm{MPa}$ with steam mass flowrate in the range of $\dot{m}=[0.033, \ldots, 1.376] \mathrm{kg} / \mathrm{s}$. To investigate the effect of the initial enthalpy on the generated power and the $\mathrm{PbP}$, the analysis is performed for two initial temperatures $\mathrm{T} 1=[535,550] \mathrm{K}$.

The graph shows the $\mathrm{PbP}$ required for a machine working 8000 working hours per year as a function of the generated power. For low electrical power the $\mathrm{PbP}$ is high. With increasing power, it approaches a constant value asymptotically. This means that the power-dependent term (Equation (11)) dominates. With increasing power generation, the function approaches a constant value given by the first term in Equation (11). The difference of $\Delta T_{1}=15 \mathrm{~K}$ causes a doubling of the generated power and consequently a significant reduction of the $\mathrm{PbP}$. Considering an uncertainty of $50 \%$ in the cost estimate, the $\mathrm{PbP}$ of these single stage turbines with an electrical output power $<200 \mathrm{~kW}$ is less than two years, therefore offering an interesting perspective from an industrial point of view. 


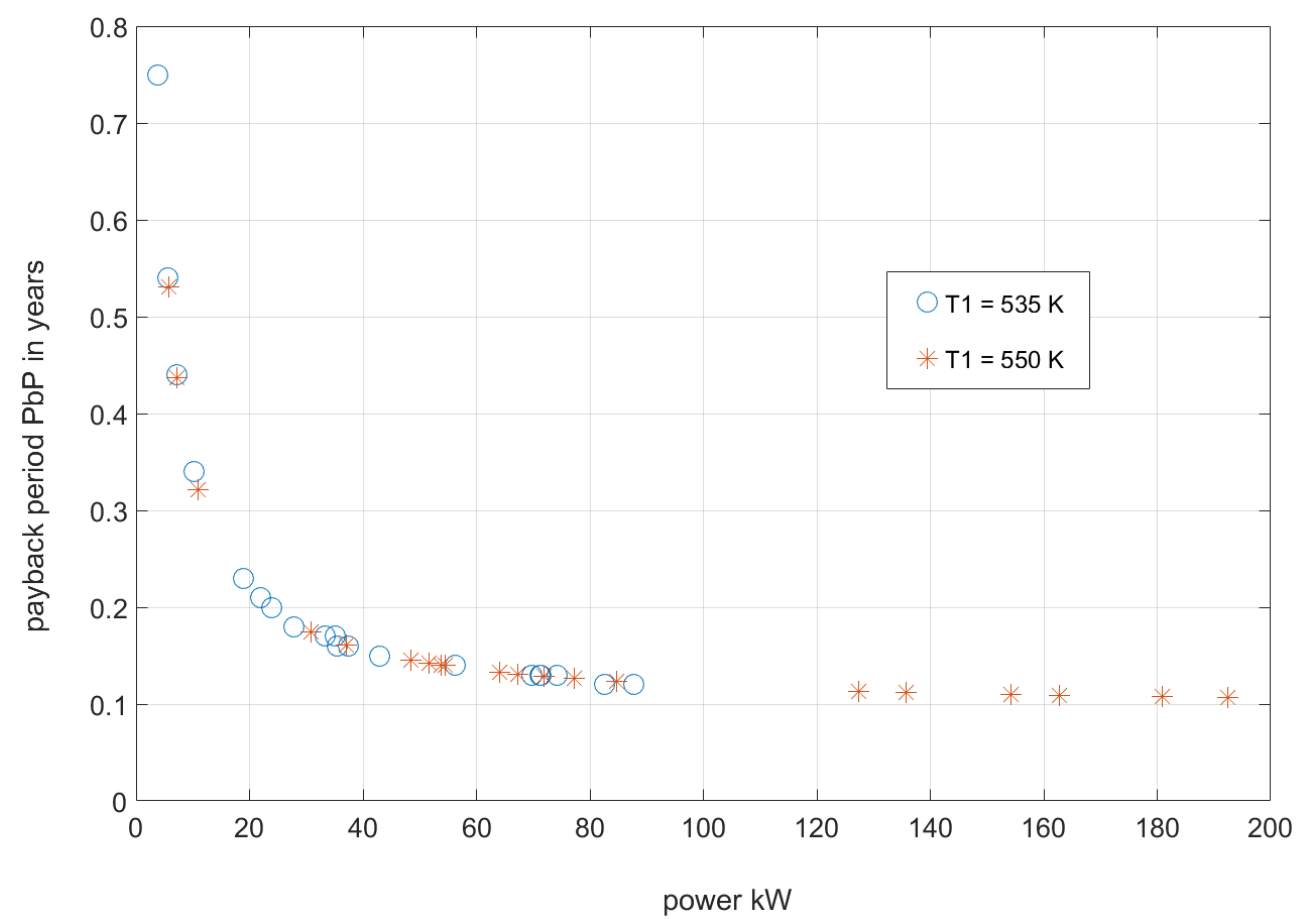

Figure 6. Analysis of available cases for two initial temperatures $T_{1}, \mathrm{PbP}$ vs. generated power for a single expansion process.

\section{Multi-Stage Expansion with Intermediate Super-Heating}

As shown in Section 2, due to the turbine efficiency, which has a typical range of $\eta_{i s}=[0.7, \ldots, 0.99]$, it is often impossible to use the entire available pressure difference in a single expansion process. However, by intermediate re-heating, several expansion processes can be carried out in succession and thus the entire pressure difference can be exploited to generate electrical energy. Using Case 1 from the previous section, the potential from multiple expansion stages is examined and shown in Figure 7.

The expansion and intermediate re-heating take place between the saturated steam line $h_{3 . x}$ and the enthalpy of the superheated steam from the steam generator $\left(h_{1}=h_{2^{\prime} \cdot x}=c^{s t}\right)$. The total number of expansion processes $\mathrm{N}$ has to be determined iteratively, with the turbine efficiency $\eta_{x}$ as parameter, $N=f\left(\Delta p, T 1, \eta_{x}\right)$. This results in four expansions $\left(h_{3 . x}-h_{2 . x}\right)$ and three intermediate heating steps $\left(h_{2 . x+1}-h_{3 . x}\right)$ where $x=[1, \ldots, 4]$ denotes the stages, as shown in the TS diagram in Figure 7. The corresponding turbine efficiencies are $\eta_{x}=(0.8,0.8,0.8,0.8)$.

The total electrical power that can be obtained from the multi-stage expansion yields

$$
P_{\Sigma}=\dot{m}_{T} \cdot \sum_{x=1}^{N}\left(h_{3 . x}-h_{2^{\prime} \cdot x}\right)
$$

The turbine mass flow $\dot{m}_{T}$ depends on the type of heat source $q_{\text {heat }}$ used for intermediate heating. If an external heat source can be used, the turbine mass flow is equal to the mass flow coming from the steam generator, yielding the upper limit for electricity generation. Another option is to split the steam from the steam generator into two separate flows $\dot{m}=\dot{m}_{T}+\dot{m}_{q}$, one to generate electrical energy and the other as heat source for the reheat processes. The resulting mass flow ratio can be calculated from the energy balance between the generated electrical power and the heat supplied as follows:

$$
\frac{\dot{m}_{q}}{\dot{m}_{T}}=\frac{\sum_{x=1}^{N-1}\left(h_{3 . x}-h_{2^{\prime} . x}\right)}{q_{\text {heat }}}
$$


This ratio depends on whether (i) either only the sensible heat of the partial mass flow $\dot{m}_{q}$ is used, or (ii) both latent and sensible heat of the steam. Since the latent heat is significantly higher than the sensible heat in the analysed case, it follows that the turbine mass flow and thus the electrical power generated is also higher, as suggested by the comparison summarized in Table 4.

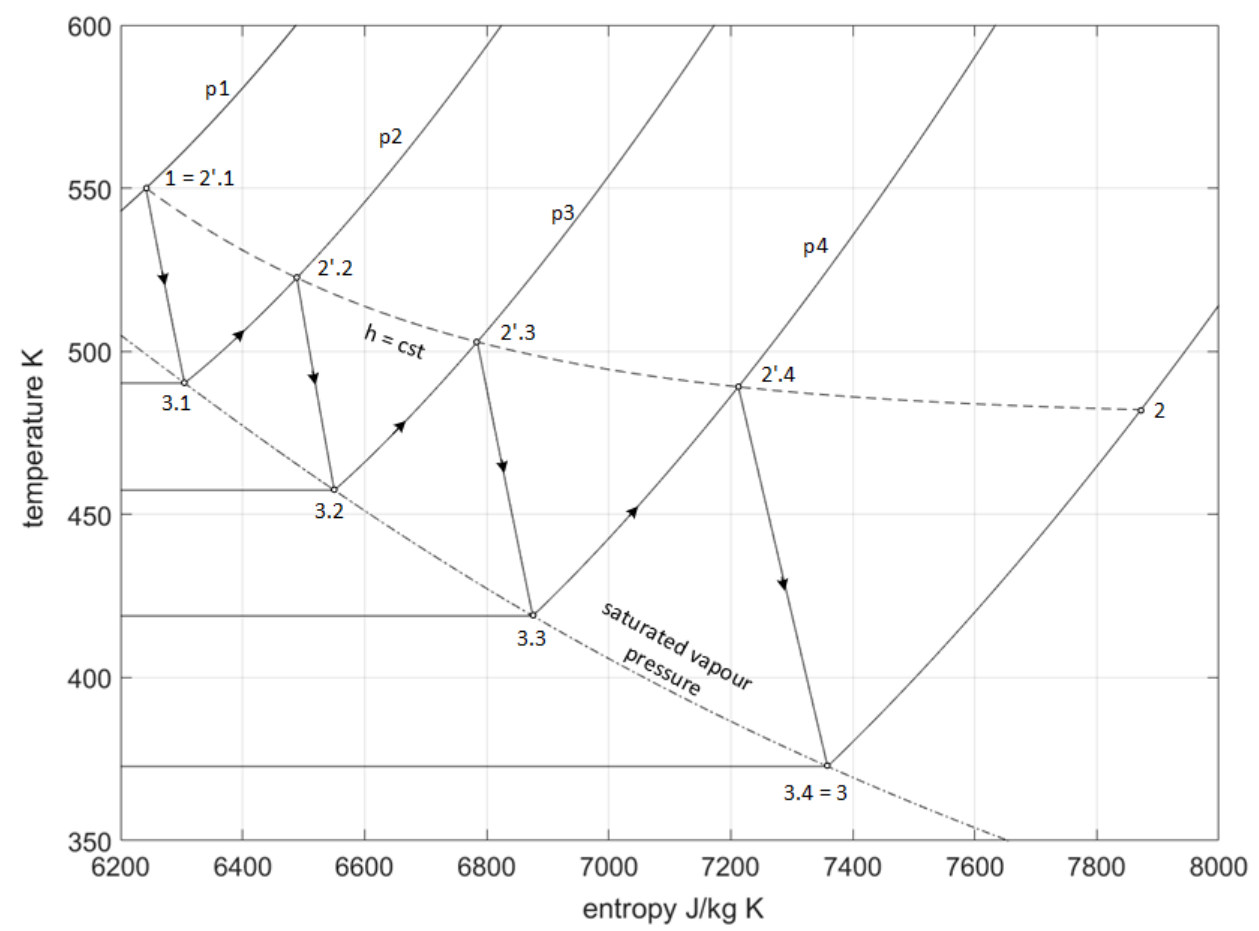

Figure 7. Four stage expansion process for a fixed turbine efficiency $\eta_{x}=(0.8,0.8,0.8,0.8)$, refer to Case 1 in Table 1.

Table 4. Generated electrical power $\frac{P_{\Sigma}}{P}$ and payback period $\frac{P b P_{m}}{P b P}$ of a multi-stage expansion for three different heat sources, the multi-stage data are normalised with their corresponding single-stage results

\begin{tabular}{lccc}
\hline Heat Source & $\frac{\dot{m}_{q}}{\dot{m}_{T}}$ & $\frac{P_{\Sigma}}{P}$ & $\frac{P b P_{m}}{P b P}$ \\
\hline External & 0 & 2.64 & 0.94 \\
Internal, sensible \& latent heat & 0.2 & 2.18 & 0.92 \\
Internal, sensible heat only & 1 & 1.32 & 0.88 \\
\hline
\end{tabular}

However, the electrical power is only $18 \%$ lower than the maximum value achievable with an external heat source used for intermediate superheating. When only sensible heat is used, the generated electrical power decreases to $50 \%$ of the maximum and represents the lower limit. The values of the multi-stage expansion presented in Table 4 are normalized with the respective values of the single-stage expansion.

In the case under investigation, four turbines and three heat exchangers (re-heaters) are required. For the turbine it is assumed that two stages can be combined in one machine, which halves the constant costs in Equation (9). It is assumed that the intermediate superheating is realized by generic shell and tube heat exchangers. Their cost can be calculated using the following equation proposed by Mounier et al. [21]:

$$
C_{H C}=C+D \cdot A^{n}
$$

where $A$ is the surface area of the heat exchanger, $C=193 C H F, D=1161 \frac{C H F}{m^{2}}$ and $n=0.9119$. To obtain a power-based relationship, the heat exchanger surface area is substituted by 


$$
A=\frac{\dot{m}_{q} \cdot q_{\text {heat }}}{U \cdot \Delta T_{l m}}
$$

where $U$ is the thermal transmittance and $\Delta T_{l m}$ the logarithmic mean temperature difference LMTD.

For a shell and tube heat exchanger, the thermal transmittance and the driving temperature difference have to be estimated in order to determine the required heat exchanger area A. The steam to be heated flows through the tubes, while the hot steam flows around them and thereby condenses. In this configuration, the heat transfer from the inner tube wall into the superheated steam (cold side) dominates the overall heat transfer, since the heat transfer coefficient for condensation around the tubes (hot side) is two orders of magnitude larger [22]. The following relation for turbulent superheated steam is used [23] to compute the heat transfer coefficient $h_{\text {cold }}$

$$
h_{\text {cold }}=\left(4.4+0.3 \cdot \frac{T_{\text {fluid }}}{100}\right)+\frac{c^{0.75}}{d^{0.25}}
$$

where $T_{\text {fluid }}$ is the bulk temperature of the steam, $\mathrm{c}$ the average velocity in the tubes and $\mathrm{d}$ the hydraulic tube diameter. Setting $h_{\text {cold }} \approx U$, a value of $U \approx 160 \frac{\mathrm{W}}{\mathrm{m}^{2} \mathrm{~K}}$ is used in Equation (15) and the LMTD is estimated from the data, yielding the extended model for the multi-stage payback period $\mathrm{PbP}_{m}$ as follows:

$$
P b P_{m}=\left(\frac{A}{E P E}+\frac{D}{E P E \cdot\left(U \cdot \Delta T_{l m}\right)^{n}} \cdot \frac{\left(\dot{m}_{q} \cdot q_{h e a t}\right)^{n}}{P_{\Sigma}}+\frac{\frac{N}{2} \cdot B+(N-1) \cdot C}{E P E} \cdot \frac{1}{P_{\Sigma}}\right)
$$

where $N$ is the number of stages. Table 4 shows the $P B P_{m}$ normalized with the singlestage expansion case. In spite of the higher complexity of the entire system, i.e., four turbine stages and three heat exchangers, the additional cost is more than compensated by the higher electrical power generated. Since the individual components of the system become smaller as the mass flow ratio increases, their cost decrease and so does the normalised $\mathrm{PbP}_{m}$. In general, the situation does not change significantly with the number of turbine stages to exploit the entire pressure range. By generating electrical energy, as an embodiment of exergy, this process moves toward making the best possible use of available energy sources. The authors are aware that multi-stage expansion with intermediate heating significantly increases the complexity and thus potential problems of such a system compared to simple throttling or single-stage expansion. However, it is important to highlight the potential for such systems and for well-informed decisions.

For the 20 available cases, Figure 8 shows the $P b P_{m}$ for multi-stage expansion as a function of the generated electrical power. Both quantities are standardized with their respective values of the single expansion. For both initial temperatures $\mathrm{T}=535 \mathrm{~K}$ (circles) and $\mathrm{T}=550 \mathrm{~K}$ (triangles), the number of expansion stages $\mathrm{N}$ required to use the full pressure range are color-coded in the legend. Note that an external heat source is assumed in the present analysis. The graph reveals that the generated power can be increased by up to 3.3 times by means of multi-stage expansion with reheat compared to a single-stage expansion combined with a throttling device. However, this requires a large number of turbine stages and heat exchangers, leading to higher system complexity. Under the given assumptions, the values of the $\mathrm{PbP}_{m}$ of multi-stage systems are at most 1.5 times higher compared to systems with only one expansion stage. Increasing future energy costs would give rise to decreasing $\mathrm{PbP}$ for multi-stage expansion systems, and make them more attractive from an economic perspective. 


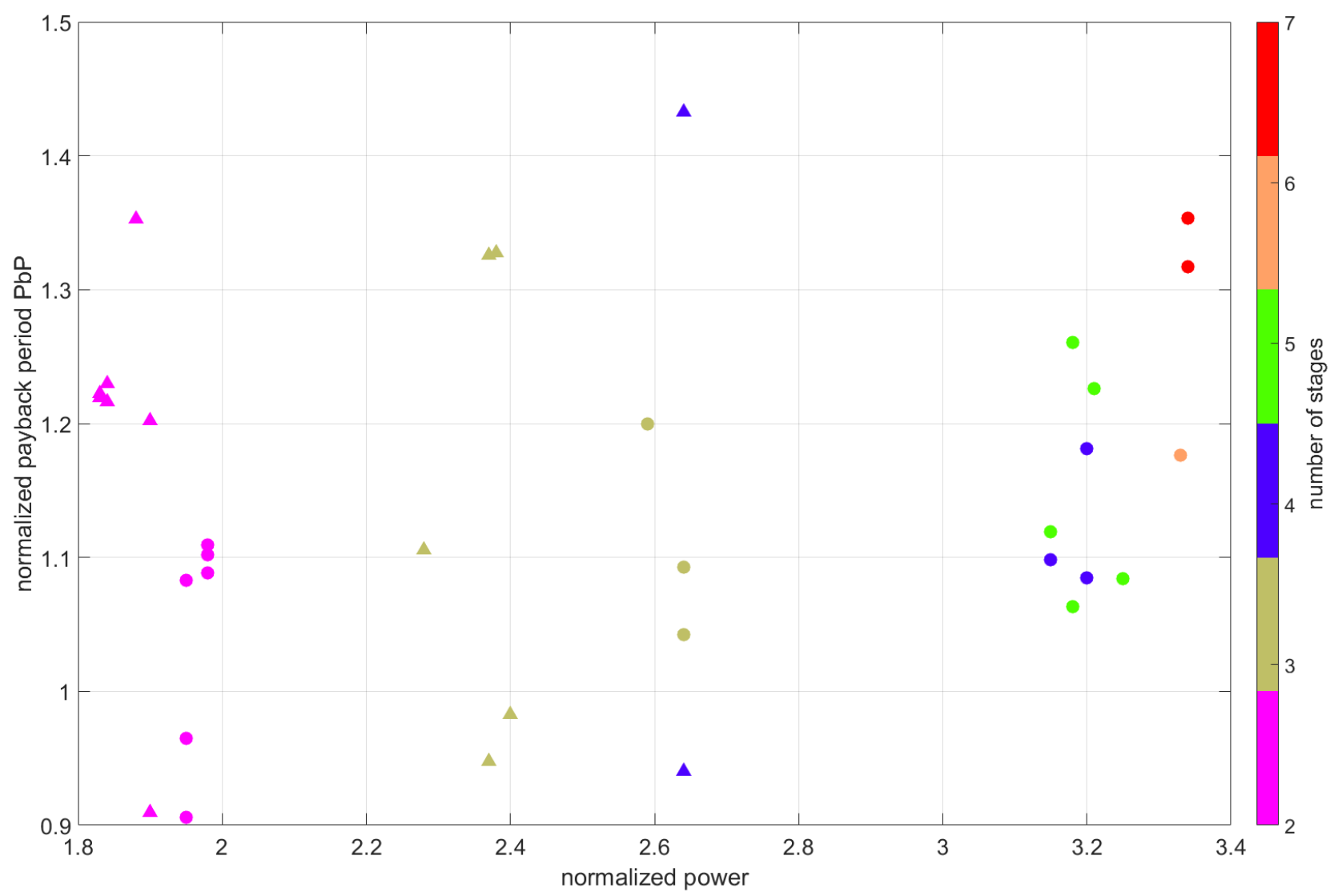

Figure 8. Analysis of available cases for two initial temperatures $T_{1}$ (Circles: $\mathrm{T}=535 \mathrm{~K}$; Triangles: $\mathrm{T}=550 \mathrm{~K}$ ), normalized payback period $\frac{P b P_{m}}{P b P}$ vs. normalized generated power $\frac{P_{\Sigma}}{P}$ for multi-stage expansion, the number of stages $\mathrm{N}$ is color-coded as shown in the legend (refer to Tables A1 and A2 in the supplementary material)

\section{Conclusions}

In this study, the use of oil-free, small-scale turbomachines in a steam conditioning process was investigated. Instead of adjusting the required pressure level of the receiving device by simple throttling, thereby transforming the available pressure difference into a low-exergy medium (heat), expansion using a turbine and generator recovers it by generating electricity. A thermodynamic assessment of a modified conditioning process was analysed and the special design features of such a turbomachine were presented, which are of critical importance for such applications.

Economic aspects of the application of small scale turbomachines have been examined using real cases from industry. The following points can be noted as the main results of the analysis:

1. Small-scale, oil-free turboexpanders can be added to many common steam conditioning processes with benefits from producing electricity. In the vast majority of cases the usable pressure ratio $\pi_{t}$ will not exceed $\pi_{t}(\eta>0.7, T 1<550 \mathrm{~K})=5.5$, so that single-stage or two-stage turbines will be sufficient (refer to Tables A1 and A2).

2. The design of the conditioning process using a small-scale turbine in conjunction with a throttle or a heat exchanger is essentially determined by the condition of the steam originating from the steam generator/process. Proper selection of the turbine outlet conditions has a significant influence on the electrical energy that can be generated. Furthermore it was shown, that it is possible to predict the power output of the turbine without knowing the exact specifications of the turbine. This is an important step for a screening analysis to examine the potential of such applications in industry. 
3. For designers of small-scale, oil-free, gas-lubricated turbomachines, prevention of steam condensation in gas bearings and around the electric machine is of key importance when designing the cooling system for the machine.

4. The payback period of the investment costs arising from the use of a small turbine generating electricity in a steam conditioning process is in the range of 6-15 operating months for the investigated cases, depending on the boundary conditions, and is therefore economically reasonable.

5. By using the entire pressure difference, up to 3.3 times more electrical energy can be generated compared to a single stage expansion, which almost compensates for the higher investment costs of such multi-stage processes.

Author Contributions: All authors contributed to conceptualization and methodology. Formal analysis, A.W. and I.K.; investigation, A.W. and I.K.; resources, J.S. and F.M.; data curation, I.K.; writing-original draft preparation, A.W. and I.K.; writing—review and editing, A.W., I.K., J.S., F.M.; visualization, A.W.; supervision, J.S. and F.M.; funding acquisition, J.S. and F.M. All authors have read and agreed to the published version of the manuscript.

Funding: This research project is financially supported by the Swiss Innovation Agency Innosuisse and is part of the Swiss Competence Center for Energy Research SCCER-EIP.

Institutional Review Board Statement: Not applicable.

Informed Consent Statement: Not applicable.

Data Availability Statement: The original contributions presented in the study are included in the article, further inquiries can be directed to the corresponding authors.

Acknowledgments: We would like to thank our industrial partners for their cooperation in providing real test cases for such applications. Additionally, exchanges with Teqtoniq GmbH, Andreas Lehr, were very helpful for estimating the cost for manufacturing turbomachinery for this application.

Conflicts of Interest: The authors declare no conflict of interest.

\section{Appendix A}

Table A1. Data set from industry steam networks at T1 = 535 K and main results for single and multi expansion.

\begin{tabular}{|c|c|c|c|c|c|c|c|c|c|c|}
\hline \multicolumn{5}{|c|}{ Input Data } & \multicolumn{3}{|c|}{ Single Expansion } & \multicolumn{3}{|c|}{ Multi Expansion } \\
\hline $\begin{array}{l}\text { Data } \\
\text { Set }\end{array}$ & $\dot{m}$ & p1 & T1 & p3 & $\pi_{t}(\eta)$ & $\mathbf{P}$ & $\mathrm{PbP}$ & $\mathbf{N}$ & $\frac{P_{\Sigma}}{P}$ & $\frac{P b P_{m}}{P b P}$ \\
\hline & $\mathrm{kg} / \mathrm{s}$ & $\times 10^{5} \mathrm{~Pa}$ & $\mathbf{K}$ & $\times 10^{5} \mathrm{~Pa}$ & - & kW & $\begin{array}{c}(8000 \\
\mathrm{OH})\end{array}$ & Stages & - & - \\
\hline 1 & 0.365 & 40 & 535 & 22.2 & $1.39(0.8)$ & 23.96 & 0.20 & 2 & 1.95 & 0.91 \\
\hline 2 & 1.087 & 40 & 535 & 22.2 & $1.39(0.8)$ & 71.41 & 0.13 & 2 & 1.95 & 1.08 \\
\hline 3 & 0.508 & 40 & 535 & 22.2 & $1.39(0.8)$ & 33.33 & 0.17 & 2 & 1.95 & 0.96 \\
\hline 4 & 0.759 & 40 & 535 & 11.05 & $1.48(0.8)$ & 69.74 & 0.13 & 4 & 3.20 & 1.18 \\
\hline 5 & 0.381 & 40 & 535 & 11.05 & $1.48(0.8)$ & 35.04 & 0.17 & 4 & 3.20 & 1.08 \\
\hline 6 & 0.242 & 40 & 535 & 4.05 & $1.96(0.8)$ & 35.40 & 0.16 & 5 & 3.21 & 1.23 \\
\hline 7 & 0.847 & 40 & 535 & 13.05 & $1.42(0.8)$ & 71.27 & 0.13 & 3 & 2.59 & 1.20 \\
\hline 8 & 0.116 & 40 & 535 & 1.7 & $2.62(0.8)$ & 21.98 & 0.21 & 6 & 3.33 & 1.18 \\
\hline 9 & 0.239 & 40 & 535 & 14.55 & $1.39(0.8)$ & 18.94 & 0.23 & 3 & 2.64 & 1.04 \\
\hline 10 & 0.392 & 40 & 535 & 10.29 & $1.5(0.8)$ & 37.42 & 0.16 & 4 & 3.15 & 1.10 \\
\hline 11 & 0.351 & 40 & 535 & 14.55 & $1.39(0.8)$ & 27.84 & 0.18 & 3 & 2.64 & 1.09 \\
\hline 12 & 0.026 & 40 & 535 & 3.76 & $2.01(0.8)$ & 3.80 & 0.75 & 5 & 3.18 & 1.06 \\
\hline 13 & 1.163 & 40 & 535 & 24.58 & $1.29(0.8)$ & 74.21 & 0.13 & 2 & 1.98 & 1.09 \\
\hline 14 & 1.376 & 40 & 535 & 24.58 & $1.29(0.8)$ & 87.81 & 0.12 & 2 & 1.98 & 1.11 \\
\hline 15 & 1.293 & 40 & 535 & 24.58 & $1.29(0.8)$ & 82.51 & 0.12 & 2 & 1.98 & 1.10 \\
\hline 16 & 0.45 & 40 & 535 & 10.29 & $1.5(0.8)$ & 42.94 & 0.15 & 5 & 3.15 & 1.12 \\
\hline 17 & 0.051 & 40 & 535 & 4.47 & $1.9(0.8)$ & 7.12 & 0.44 & 5 & 3.25 & 1.08 \\
\hline 18 & 0.374 & 40 & 535 & 3.76 & $2.01(0.8)$ & 56.21 & 0.14 & 5 & 3.18 & 1.26 \\
\hline 19 & 0.223 & 40 & 535 & 1 & $3.13(0.8)$ & 37.49 & 0.16 & 7 & 3.34 & 1.35 \\
\hline 20 & 0.034 & 40 & 535 & 1 & $3.13(0.8)$ & 5.62 & 0.54 & 7 & 3.34 & 1.32 \\
\hline
\end{tabular}


Table A2. Data set from industry steam networks at $\mathrm{T} 1=550 \mathrm{~K}$ and main results for single and multi expansion.

\begin{tabular}{|c|c|c|c|c|c|c|c|c|c|c|}
\hline \multirow{3}{*}{$\begin{array}{l}\text { Data } \\
\text { Set }\end{array}$} & \multicolumn{3}{|c|}{ Input Data } & \multicolumn{4}{|c|}{ Single Expansion } & \multicolumn{3}{|c|}{ Multi Expansion } \\
\hline & $\dot{m}$ & p1 & T1 & p3 & $\pi_{t}(\eta)$ & $\mathbf{P}$ & $\mathrm{PbP}$ & $\mathbf{N}$ & $\frac{P_{\Sigma}}{P}$ & $\frac{P b P_{m}}{P b P}$ \\
\hline & kg/s & $\begin{array}{c}\times 10^{5} \\
\mathrm{~Pa}\end{array}$ & $\mathbf{K}$ & $\begin{array}{c}\times 10^{5} \\
\mathrm{~Pa}\end{array}$ & - & kW & $\begin{array}{c}(8000 \\
\mathrm{OH})\end{array}$ & Stages & - & - \\
\hline 1 & 0.365 & 40 & 550 & 22.2 & $1.82(0.75)$ & 33.63 & 0.169 & 1 & 1 & 0.169 \\
\hline 2 & 1.087 & 40 & 550 & 22.2 & $1.82(0.75)$ & 100.21 & 0.119 & 1 & 1 & 0.119 \\
\hline 3 & 0.508 & 40 & 550 & 22.2 & $1.82(0.75)$ & 46.78 & 0.148 & 1 & 1 & 0.148 \\
\hline 4 & 0.759 & 40 & 550 & 11.05 & $2.08(0.75)$ & 82.86 & 0.124 & 2 & 1.843 & 1.23 \\
\hline 5 & 0.381 & 40 & 550 & 11.05 & $2.08(0.75)$ & 41.63 & 0.154 & 2 & 1.843 & 1.217 \\
\hline 6 & 0.242 & 40 & 550 & 4.05 & $2.84(0.75)$ & 34.99 & 0.166 & 3 & 2.382 & 1.328 \\
\hline 7 & 0.847 & 40 & 550 & 13.05 & $2.01(0.75)$ & 88.23 & 0.123 & 2 & 1.878 & 1.353 \\
\hline 8 & 0.116 & 40 & 550 & 1.7 & $3.88(0.75)$ & 20.01 & 0.219 & 3 & 2.283 & 1.106 \\
\hline 9 & 0.239 & 40 & 550 & 14.55 & $1.95(0.75)$ & 24.11 & 0.198 & 2 & 1.901 & 0.91 \\
\hline 10 & 0.392 & 40 & 550 & 10.29 & $2.12(0.75)$ & 43.71 & 0.151 & 2 & 1.833 & 1.22 \\
\hline 11 & 0.351 & 40 & 550 & 14.55 & $1.95(0.75)$ & 35.43 & 0.165 & 2 & 1.901 & 1.203 \\
\hline 12 & 0.026 & 40 & 550 & 3.76 & $2.91(0.75)$ & 3.73 & 0.766 & 3 & 2.37 & 0.948 \\
\hline 13 & 1.163 & 40 & 550 & 24.58 & $1.62(0.9)$ & 105.77 & 0.118 & 1 & 1 & 0.118 \\
\hline 14 & 1.376 & 40 & 550 & 24.58 & $1.62(0.9)$ & 125.15 & 0.114 & 1 & 1 & 0.114 \\
\hline 15 & 1.293 & 40 & 550 & 24.58 & $1.62(0.9)$ & 117.59 & 0.116 & 1 & 1 & 0.116 \\
\hline 16 & 0.45 & 40 & 550 & 10.29 & $2.12(0.75)$ & 50.16 & 0.144 & 2 & 1.833 & 1.223 \\
\hline 17 & 0.051 & 40 & 550 & 4.47 & $2.74(0.75)$ & 7.14 & 0.445 & 3 & 2.4 & 0.983 \\
\hline 18 & 0.374 & 40 & 550 & 3.76 & $2.91(0.75)$ & 55.03 & 0.14 & 3 & 2.37 & 1.326 \\
\hline 19 & 0.223 & 40 & 550 & 1 & $4.73(0.75)$ & 48.49 & 0.146 & 4 & 2.64 & 1.433 \\
\hline 20 & 0.034 & 40 & 550 & 1 & $4.23(0.8)$ & 7.28 & 0.438 & 4 & 2.64 & 0.94 \\
\hline
\end{tabular}

Table A3. Turbine radius $\mathrm{r} 4$ and rotational speed $N_{\text {turb }}$ for single expansion, based on the data sets from industry in Tables A1 and A2.

\begin{tabular}{|c|c|c|c|c|c|c|c|c|}
\hline \multicolumn{3}{|c|}{ Input Data } & \multicolumn{3}{|c|}{$\mathrm{T} 1=535 \mathrm{~K}$} & \multicolumn{3}{|c|}{$\mathrm{T}=550 \mathrm{~K}$} \\
\hline Data Set & $\begin{array}{c}\mathrm{dm} / \mathrm{dt} \\
\mathrm{kg} / \mathrm{s}\end{array}$ & $\begin{array}{c}\mathrm{p} 3 \\
\times 10^{5} \mathrm{~Pa}\end{array}$ & $\pi_{t}(\eta)$ & $\begin{array}{c}r 4 \\
\mathrm{~mm}\end{array}$ & $\begin{array}{c}N_{t u r b} \\
\text { rpm }\end{array}$ & $\pi_{t}(\eta)$ & $\begin{array}{c}r 4 \\
\mathrm{~mm}\end{array}$ & $\begin{array}{c}N_{t u r b} \\
\text { rpm }\end{array}$ \\
\hline 1 & 0.365 & 22.2 & $1.39(0.8)$ & 20.6 & 92,938 & $1.82(0.75)$ & 16.9 & 170,039 \\
\hline 2 & 1.087 & 22.2 & $1.39(0.8)$ & 34.1 & 56,250 & $1.82(0.75)$ & 29.1 & 97,594 \\
\hline 3 & 0.507 & 22.2 & $1.39(0.8)$ & 24.3 & 78,856 & $1.82(0.75)$ & 26.1 & 144,275 \\
\hline 4 & 0.758 & 11.05 & $1.48(0.8)$ & 38.2 & 60,219 & $2.08(0.75)$ & 32.4 & 98,267 \\
\hline 5 & 0.381 & 11.05 & $1.48(0.8)$ & 27.0 & 85,048 & $2.08(0.75)$ & 22.9 & 138,844 \\
\hline 6 & 0.242 & 4.05 & $1.96(0.8)$ & 30.5 & 97,657 & $2.84(0.75)$ & 27.2 & 137,296 \\
\hline 7 & 0.847 & 13.05 & $1.42(0.8)$ & 37.3 & 71,018 & $2.01(0.75)$ & 32.5 & 95,375 \\
\hline 8 & 0.116 & 1.7 & $2.62(0.8)$ & 29.4 & 119,122 & $3.88(0.75)$ & 26.8 & 156,401 \\
\hline 9 & 0.238 & 14.55 & $1.39(0.8)$ & 19.4 & 109,950 & $1.95(0.75)$ & 16.2 & 187,786 \\
\hline 10 & 0.392 & 10.29 & $1.5(0.8)$ & 28.0 & 84,154 & $2.12(0.75)$ & 24.0 & 134,502 \\
\hline 11 & 0.350 & 14.55 & $1.39(0.8)$ & 23.5 & 90,667 & $1.95(0.75)$ & 19.7 & 154,852 \\
\hline 12 & 0.025 & 3.76 & $2.01(0.8)$ & 10.1 & 300,502 & $2.91(0.75)$ & 9.0 & 419,720 \\
\hline 13 & 1.163 & 24.58 & $1.29(0.8)$ & 34.7 & 56,038 & $1.62(0.9)$ & 28.6 & 100,495 \\
\hline 14 & 1.376 & 24.58 & $1.29(0.8)$ & 37.8 & 51,518 & $1.62(0.9)$ & 31.0 & 92,592 \\
\hline 15 & 1.293 & 24.58 & $1.29(0.8)$ & 36.7 & 53,047 & $1.62(0.9)$ & 30.1 & 95,309 \\
\hline 16 & 0.450 & 10.29 & $1.5(0.8)$ & 30.0 & 78,561 & $2.12(0.75)$ & 25.7 & 125,535 \\
\hline 17 & 0.051 & 4.47 & $1.9(0.8)$ & 13.5 & 215,833 & $2.74(0.75)$ & 12.1 & 304,690 \\
\hline 18 & 0.374 & 3.76 & $2.01(0.8)$ & 39.0 & 77,693 & $2.91(0.75)$ & 34.9 & 108,326 \\
\hline 19 & 0.222 & 1 & $3.13(0.8)$ & 50.4 & 75,057 & $4.73(0.75)$ & 48.7 & 94,693 \\
\hline 20 & 0.033 & 1 & $3.13(0.8)$ & 19.4 & 194,675 & $4.23(0.8)$ & 20.7 & 262,588 \\
\hline
\end{tabular}

\section{References}

1. Hackl, R.; Harvey, S. Identification, Cost Estimation and Economic Performance of Common Heat Recovery Systems for the Chemical Cluster in Stenungsund; Technical Report; Department of Energy and Environment, Chalmers University of Technology: Göteborg, Sweden, 2013. 
2. Turbonik GmbH. 2018. Available online: www.turbonik.de (accessed on 2 January 2021).

3. Epstein, A.H. Millimeter-Scale, Micro-Electro-Mechanical Systems Gas Turbine Engines. ASME J. Eng. Gas Turbines Power 2004, 126, 205-225. [CrossRef]

4. Isomura, K.; Murayama, M.; Teramoto, S.; Hikichi, K.; Endo, Y.; Togo, S.; Tanaka, S. Experimental Verification of the Feasibility oa 100 W Class Micro-Scale Gas Turbine at an Impeller Diameter of 10mm. J. Micromech. Microeng. 2006, 16, S254-S261. [CrossRef]

5. Schiffmann, J.; Favrat, D. Experimental Investigation of a Direct Driven Radial Compressor for Domestic Heat Pumps. Int. J. Refrig. 2009, 32, 1918-1928. [CrossRef]

6. Demierre, J.; Rubino, A.; Schiffmann, J. Modeling and Experimental Investigation of an Oil-Free Microcompressor-Turbine Unit for an Organic Rankine Cycle Driven Heat Pump. Trans. ASME J. Eng. Gas Turbines Power 2015, 137, 032602. [CrossRef]

7. Wagner, P.; Van herle, J.; Schiffmann, J. Theoretical and Experimental Investigation of a 34 Watt Radial-Inflow Steam Turbine with Partial-Admission. J. Eng. Gas Turbines Power 2021, 143, 081002. [CrossRef]

8. Rosset, K.; Pajot, O.; Schiffmann, J. Experimental Investigation of a Small-Scale Organic Rankine Cycle Turbo-Generator Supported on Gas-Lubricated Bearings. J. Eng. Gas Turbines Power 2021, 143, 051015. [CrossRef]

9. Schiffmann, J.; Favrat, D. Integrated Design and Optimization of Gas Bearing Supported Rotors. J. Mech. Des. 2010, $132,051007$. [CrossRef]

10. Casey, M. Lecture Notes: Turbocharger TC, Chapter 4: Turbines; ITSM, Institut für Thermische Strömungsmaschinen und Maschinenlaboratiorium, Unitversität Stuttgart: Stuttgart, Germany, 2008.

11. Baehr, H.D. Thermodynamik, 8th ed.; Springer-Lehrbuch: Berlin/Heidelberg, Germany; New York, NY, USA; Tokyo, Japan, 1992.

12. Wagner, P.H.; Wuillemin, Z.; Constantin, D.; Diethelm, S.; Van herle, J.; Schiffmann, J. Experimental characterization of a solid oxide fuel cell coupled to a steam-driven micro anode off-gas recirculation fan. Appl. Energy 2020, 262, 114219. [CrossRef]

13. Guenat, E.; Schiffmann, J. Thin Gas Film Isothermal Condensation in Aerodynamic Bearings. J. Tribol. 2019, 141, 111701. [CrossRef]

14. Schiffmann, J.; Kontomaris, K.; Arpagaus, C.; Bless, F.; Bertsch, S. Scale limitations of gas bearing supported turbocompressors for vapor compression cycles. Int. J. Refrig. 2020, 109, 92-104.. [CrossRef]

15. Katuwal Chhetri, S. Numerical and Experimental Investigations on Non-Contacting Seals for Small-Scale Applications. Ph.D. Thesis, École Polytechnique Fédérale de Lausanne, Lausanne, Switzerland, 2020.

16. Industrial Partners. (Anonymous). Personal communication, 2020.

17. Williams, R.J. 'Six-Tenth Factor' Aids in Approximating Costs. J. Chem. Eng. Data 1947, 54, 124-125.

18. Peters, M.S.; Timmerhaus, K.D. Plant Design and Economics for Chemical Engineers, 5th ed.; McGraw-Hill: New York, NY, USA, 2002.

19. Guenat, E.; Schiffmann, J. Multi-Objective Optimization of Grooved Gas Journal Bearings for Robustness in Manufacturing Tolerances. Tribol. Trans. 2019, 62, 1041-1050. [CrossRef]

20. Eidgenössische Elektrizitätskommission ELCom. Strompreise Schweiz. 2020. Available online: https://www.elcom.admin.ch (accessed on 1 May 2020).

21. Mounier, V.; Mendoza, L.C.; Schiffmann, J. Thermo-economic optimization of an ORC driven heat pump based on small scale turbomachinery and comparison with absorption heat pumps. Int. J. Refrig. 2017, 81, 96-110. [CrossRef]

22. Herwig, H. Wärmeübertragung A-Z, Systematische und Ausführliche Erläuterungen Wichtiger Größen und Konzepte, VDI-Buch; Springer: Berlin/Heidelberg, Germany, 2000

23. Schramek, R.; Recknagel, H. Taschenbuch für Heitzung + Klimatechnik; Vulkan-Verlag GmbH: Essen, Germany, 2014. 